\title{
Arteriovenous Malformations in Hereditary Haemorrhagic Telangiectasia
}

\section{Malformações Arteriovenosas na Telangiectasia Hemorrágica Hereditária}

Klaus Loureiro IRION ${ }^{1}$, Giordano Rafael Tronco ALVES ${ }^{1}$

Acta Med Port 2014 Jul-Aug;27(4):530-530

Keywords: Arteriovenous Malformations; Telangiectasia, Hereditary Hemorrhagic; Tomography, X-Ray Computed.

Palavras-chave: Malformações Arteriovenosas; Telangiectasia Hemorrágica Hereditária; Tomografia Computorizada.
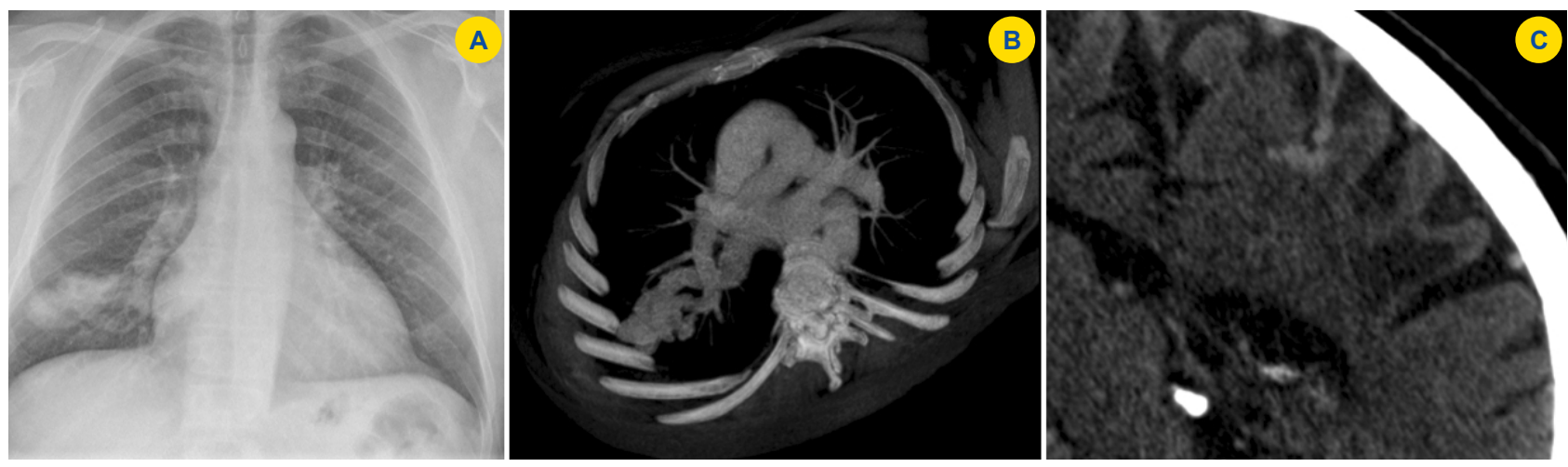

Figure 1 - (A) Rounded homogeneous opacity in the right lower lobe at radiograph frontal view. (B) Inferior view of the chest computed tomography (CT) scans demonstrating the arteriovenous malformations (AVMs) in the right lung. (C) CT study of the head revealing the presence of cerebral AVMs.

A non-smoker 61-year-old man presented with insidious shortness of breath and a history of chronic epistaxis for approximately three decades. The initial investigation revealed right basal crackles at auscultation, very subtle oral telangiectasia and a microcytic anaemia. A chest radiograph (Fig. 1A) demonstrated right basal rounded opacities communicating with the hilum. Further computed tomography scans of the chest (Fig. 1B) and brain (Fig. 1C) have confirmed the presence of multiple arteriovenous malformations (AVMs), suggesting Hereditary Haemorrhagic Telangiectasia (HHT, Osler-Weber-Rendu disease).
HHT is an autosomal dominant inherited disease that affects the vascular endothelium. ${ }^{1}$ Patients usually exhibits a positive family history. Due to social issues, this information could not be obtained in the illustrated case. Telangiectasia, AVMs or larger arteriovenous fistulae can either be noticed at physical examination or at imaging assessment. ${ }^{2}$ The developments of pulmonary or cerebral AVMs are known complications in patients with HHT. While endovascular treatment with AVMs embolization is the most adopted intervention, the size and the location of the lesions should determine the best approach.

\section{REFERENCES}

1. Faughnan ME, Palda VA, Garcia-Tsao G, Geisthoff UW, McDonald J, Proctor DD, et al. International guidelines for the diagnosis and management of hereditary haemorrhagic telangiectasia. J Med Genet. 2011;48:73-87.

2. Giordano P, Lenato GM, Suppressa P, Lastella P, Dicuonzo F, Chiumarulo L, et al. Hereditary hemorrhagic telangiectasia: arteriovenous malformations in children. J Pediatr. 2013;163:179-186. 
Klaus Loureiro IRION, Giordano Rafael Tronco ALVES

\title{
Arteriovenous Malformations in Hereditary Haemorrhagic Telangiectasia Acta Med Port 2014:27:530-530
}

Publicado pela Acta Médica Portuguesa, a Revista Científica da Ordem dos Médicos

\author{
Av. Almirante Gago Coutinho, 151 \\ 1749-084 Lisboa, Portugal. \\ Tel: +351218428 215
}

E-mail: submissao@actamedicaportuguesa.com

www.actamedicaportuguesa.com

ISSN:0870-399X | e-ISSN: 1646-0758

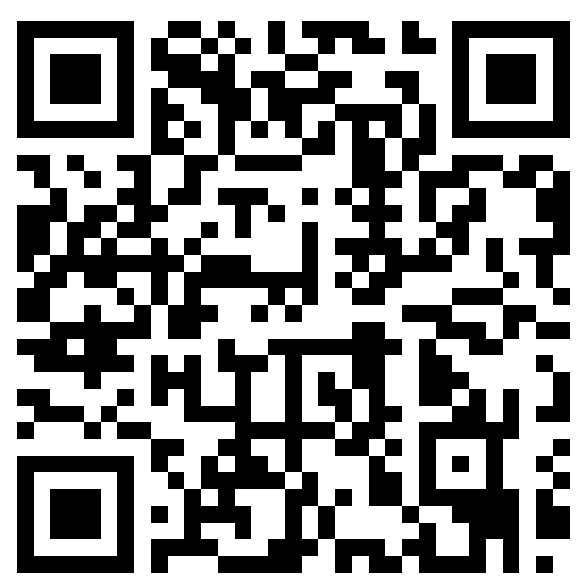

